\title{
Akıllı evler için sesli komut algılama yöntemleri
}

\author{
Hüseyin GÜNEŞ ${ }^{*}$, Sabri BİCAKCI \\ Balıkesir Üniversitesi, Mühendislik Fakültesi, Mekatronik Mühendisliği Bölümü, \\ Çağış Yerleşkesi, Balıkesir \\ Geliș Tarihi (Recived Date): 12.01.2018 \\ Kabul Tarihi (Accepted Date): 27.04.2018
}

\section{Özet}

Akıllı ev sistemi evin aydınlatma, güvenlik, havalandırma, sicaklık vb. sistemlerinin kullanicu tarafindan daha kolay kontrol ve takip edilebilmesini sağlamaktadır. Günümüzde birçok araştırmacı ve teknoloji şirketi akıllı evler üzerine çalışmalar yürütmektedir. Çalışmaların bir alanı da akıllı evlerin sesli komutlar ile herhangi bir kumanda aletine gerek kalmadan yönetilebilmesidir. Sesli komutlar ile bir sistemin yönetilmesi için 1950'lerden başlayarak günümüze kadar birçok çalışma yapılmış ve yöntem geliştirilmiştir. Bu çalışmada da bugüne değin alanda yapılmış çalışmalar ve çalışmalar sonucunda ortaya çıkmış algoritma, ürün, servis vb. incelenmiş, bunların bir akıllı ev sisteminin sesli komutlar ile çalışabilmesi için hangi durumlarda kullanılabileceği ve hangi durumlarda ne gibi avantaj ve dezavantajlara sahip olduğu araştırılmıştır.

Anahtar kelimeler: Akıllı ev, konuşma tanıma, ses tanıma.

\section{Voice command recognition methods for smart houses}

\begin{abstract}
The smart home system allows the user to more easily control and monitor the lighting, security, ventilation, air conditioning etc. systems of a house. Today, many researchers and technology company are conducting studies on smart homes. One area of the studies is that smart homes can be managed with voice commands without the need for any control devices. From the 1950s to now, a lot of work has been done to manage a system with voice commands and many methods have been developed. In this study, the studies made in the field up to today and the algorithms, products, services etc. that emerged as the result of these studies are examined. It has been researched that which
\end{abstract}

\footnotetext{
*Hüseyin GÜNEŞ, hgunes@balikesir.edu.tr, http://orcid.org/0000-0001-6927-5123

Sabri BİCAKCI, sbicakci@balikesir.edu.tr, http://orcid.org/0000-0002-2334-8515
} 
cases they can be used in order for a smart home system to work with voice commands and what are the advantages and disadvantages of them in which situation.

Keywords: Smart home, speech recognition, voice recognition.

\section{Giriş}

İnsanlar yaşamlarını sürdürdükleri evlerde kullanılmak üzere ilk çağlardan günümüze ihtiyaçlarına uygun olarak birçok araç-gereç geliştirmiş ve kullanmıştır. Son yüzyılda teknolojinin gelişimi ile birlikte hayatın diğer alanlarında olduğu gibi bu alanda da gelişim hızla artmış ve evlerde kullanılmak üzere çamaşır makinası, bulaşık makinası, televizyon, kahve makinası, mutfak robotu vb. birçok yeni araç geliştirilmiş ve bu araçlar evlerde standart olarak kullanılır hale gelmiştir. Yakın zamanda ise bu araçlar teknolojik açıdan geliştirilerek akıllı olarak nitelendirilen özellikler kazandırılmıştır. Ayrıca bu standart araçlar yanında akıllı olarak nitelendirilen birçok yeni ev aleti (akıllı kilit, akıllı güvenlik kamerası vb.) de evlerde yerlerini almıştır. Günümüzde ise bu ev aletlerinin ve araçların sayısının artmasıyla birlikte tüm bu ev donanımlarını tek bir noktadan kontrol ihtiyacı ortaya çıkmış ve dolayısıyla bu ihtiyaç ile birlikte akıllı ev kavramı ortaya çıkmıştır.

Akıllı ev, bir merkezden kontrol edilebilen, birbirleriyle haberleşebilen, ilişki kurabilen ve bütün bu teknolojiler sayesinde kişilere daha tasarruflu, daha güvenli, daha konforlu, ihtiyaçlara cevap verebilen ve hayatı kolaylaştıran imkânlar sunan evler olarak tanımlamıştır [1]. Akıllı evler genellikle cep telefonu, tablet, bilgisayar ya da o akıllı ev sistemi için geliştirilmiş özel kumanda aletleriyle kontrol edilmektedir. Bunun yanında araştırmacılar ve çeşitli teknoloji firmaları da günümüzde sesle kontrol edilebilen akıllı ev çalışmaları yürütmektedirler [2]. Bu çalışmada da günümüzde gerçekleştirilecek bir akıllı ev sisteminin ses ile kontrol edilebilmesi için hangi yöntemlerin kullanılabileceği ve bu yöntemlerin birbirlerine göre avantaj ve dezavantajları sunulacaktır.

\section{Literatür}

Akıllı evlerde ya da diğer alanlarda kişilerden sesli komutlar alarak işlem yapabilmek için konuşma tanıma işlemleri gerçekleştirilmesi gerekmektedir. Konuşma tanıma konuşma sinyallerinden otomatik olarak dilsel bilgilerin çıkarılması olarak tanımlanmıştır [3]. 1950'li yıllarda ilk çalışmaları yapılmaya başlanmış olup günümüzde hala üzerinde çalışılan bir araştırma konusudur. Bu zamana kadar dinamik programlama ile başlayan konuşma tanıma araştırmalarında birçok alternatif yöntem geliştirilmiştir [4].

Konuşma tanıma işleminin temeli, girdi olarak verilen seslerin, daha önce kaydedilmiş mevcut seslerle fonem ya da kelime düzeyinde karşılaştırılmasına dayanmaktadır. Ayrıca dil yapısına göre fonemlerin ya da kelimelerin önce ve sonra gelmeleri ile sık kullanımları gibi verilerde konuşma tanıma sürecinde kullanılabilmektedir [5].

Konuşma tanıma sistemleri yapıları ve yöntemleri itibariyle çeşitli dallara ayrılmaktadır. Bu dallanmalar konuşmacıya göre konuşmacıya bağımlı ya da konuşmacıdan bağımsız, ses analizine göre fonem ya da kelime tabanlı ve amaca göre ayrık veya süreklidir. 
Konuşmacıya bağımlı sistem yalnızca bir kişinin sesine göre konuşma tanıma yapabilmektedir, konuşmacıdan bağımsız sistemler ise herhangi bir kişiye göre konuşma tanıma işlemi gerçekleştirebilmektedir. Fonem tabanlı sistemler de karşılaştırma yapılan ve tanınmaya çalışılan en küçük ses öbeği fonemdir, kelime tabanlılarda ise kelimedir. Sistemin ayrık ya da sürekli olması ise konuşma tanıma sisteminin hedefi ile ilgilidir. Hedef kısa aralıklarla seslendirilen konuşmaların tanınması ise sistem ayrık tabanlı, sürekli olarak konuşma devam ederken sistem tanıma işlemi gerçekleştiriyorsa süreklidir [6].

Konuşma tanıma işlemi, insan konuşması sonucu oluşan sesin mikrofon ile elektronik ortama aktarılmasıyla başlamaktadır. Bu işlemin ardından ses sinyali sinyal işleme yöntemleri ve çeşitli matematiksel yöntemlerle işlenerek sayısal veri (öznitelik vektörü) haline getirilir. $\mathrm{Bu}$ işlem sürekli tekrarlanarak tanınması istenen konuşmaların bir veritabanı oluşturulur. Son olarak yeterli bir veri kaynağı oluşturulduğunda tanınması istenilen konuşma aynı şekilde mikrofondan alınır, sayısallaştırılır ve veritabanında daha önce sayısallaştırılmış konuşma verileri ile karşılaştırılır. Veriler eşleştiğinde konuşma tanıma işlemi gerçekleştirilmiş olur [7].

Konuşmacıdan gelen sesin mikrofon ile kaydedilerek sayısallaştırması ve öznitelik vektörü çıkartılmasında genellikle Doğrusal Öngörü Kodlama (LPC), Mel Frekans Kepstral Katsayıları (MFCC) ve Algısal Doğrusal Öngörü (PLP) kullanılmaktadır [3]. Oluşturulan öznitelik vektörlerinin karşılaştırılmasında ise Saklı Markov Modeli (HMM), yapay sinir ağları (ANN), destek vektör makinaları (SVM), olasılıksal sinir ağları (PNN), Gaussian Mixture modeli (GMM) ve farklı birçok yöntem kullanılmaktadır [8].

Akıllı ev sistemlerinde konuşma tanıma yapabilmek için daha önce bahsedildiği gibi en baştan başlanarak; ses mikrofon ile alınarak bilgisayara aktarılıp, öznitelik vektörü çıkartılıp veri setleri oluşturulduktan sonra yine daha önce bahsedilen çeşitli yöntemlerle konuşma tanıma işlemi gerçekleştirilebilir. Ancak günümüzde akıllı evlerde kullanılabilecek daha üst seviyeli farklı konuşma tanıma yöntemleri de bulunmaktadır. Bunlar;

- Çeşitli yapay zekâ kütüphaneleri,

- Konuşma tanıma kütüphaneleri ve yazılımları,

- Konuşma tanıma için özelleştirilmiş donanımlar,

- Bulut konuşma tanıma hizmetleri.

\subsection{Yapay zekâ kütüphaneleri}

Son yıllarda yapay zekâ alanında yapılan çalışmalar büyük artış göstermiştir. Bunun sonucu olarak birçok araştırmacı ve teknoloji şirketi çeşitli yapay zekâ yazılımları geliştirmişler, hatta bunların birçoğunu açık kaynak olarak diğer insanların da kullanımına sunmuşlardır. Bunlara örnek olarak Tensor Flow (Google), DMTK (Microsoft), SystemML (IBM), Torch, Caffe, Keras, Theano vb. gösterilebilir [9]. Bu yapay zekâ kütüphaneleri ile konuşma tanıma yapabilmek için kaydedilen seslerle önce kütüphane eğitilmelidir. Daha sonra konuşma tanıma işlemi kütüphane aracılığıyla gerçekleştirilebilmektedir.

\subsection{Konuşma tanıma kütüphaneleri \& yazılımları}

Yapay zekâ kütüphaneleri birçok farklı yapay zekâ işlemi için geliştirilmişlerdir. Ancak hâlihazırda yalnızca konuşma tanıma için geliştirilmiş açık kaynak kütüphaneler ve 
yazılımlar da bulunmaktadır. CMUSPhinx gibi kütüphaneler geliştirilecek olan yazılımın içinde kullanılabilirken, Kaldi, Simon gibi açık kaynak yazılımlar ise çeşitli değişiklikler yapılarak konuşma tanıma için projelerde doğrudan kullanılabilir [10].

\subsection{Konuşma tanıma için özelleştirilmiş donanımlar}

Konuşma tanıma için geliştirilmiş yazılımlar dışında bu yazılımların gerçekleştirdikleri işlemleri çok daha hızlı gerçekleştirebilen çeşitli donanımlarda bulunmaktadır. Bu tür donanımların bazıları RSC-4x serisi [11] vb. işlemci yongalarından, bazıları bu tür işlemcilerle oluşturulmuş HM2007 [12,13] vb. konuşma tanıma kitlerinden, bazıları ise akıllı evlerde sık kullanılan donanımlara (Arduino vb.) uygun olan EasyVR Shield [14], C5535 eZdsp vb. [15] eklentilerden oluşmaktadır.

\subsection{Bulut konuşma tanıma hizmetleri}

Konuşma tanıma için kullanılabilecek en kolay yöntemlerden biri de bulut konuşma tanıma hizmetlerini kullanmaktır. Büyük teknoloji firmalarından Google, Microsoft ve Amazon başta olmak üzere farklı firmaların bu tür hizmetleri bulunmaktadır [16]. Bu hizmetler kaydedilen seslerin kendi uygulama programlama arayüzleri kullanılarak yazıya dönüştürülmesini sağlamaktadır. Ayrıca bu firmaların geliştirdiği mikrofonu olan ve bu bulut servisleri kullanarak doğrudan konuşma tanıma işlemi gerçekleştirebilen donanımlar da bulunmaktadır (Amazon Echo, Athom Homey vb.) [17].

Şu ana kadar sunulan konuşma tanıma yöntemleri yanında bu yöntemlerin birçoğunu bir arada kolayca kullanmaya yarayan çeşitli yazılım kütüphaneleri de geliştirilmiştir. Bu tür yazılımlar, kullanıcıya seçenekleri sunmakta, kullanıcılar da hangi yöntemi veya servisi kullanmak istiyorsa bunu belirleyerek konuşma tanıma işlemini gerçekleştirebilmektedir [18].

\section{Tartışma}

Akıllı evlerde kullanılabilecek bir konuşma tanıma sistemi geliştirebilmek için kullanılabilecek birçok farklı yöntem ve bu yöntemlerin farklı durumlara göre avantaj ve dezavantajları bulunmaktadır. Kullanılacak en doğru yönteme karar verebilmek için öncelikle şu sorulara cevap verilmelidir:

- Sistemi kim ya da kimler kullanacak?

- Sistem belirli sayıda sesli komutla mı yoksa akıcı bir konuşma ile mi çalışacak?

Ayrıca bu sorular yanında, sistem sürekli olarak internete bağlı olacak mı, konuşma dili önemli mi, kullanılacak donanımların işlem kapasiteleri ve hafizaları ne düzeyde olacak, donanımların enerji ihtiyacı önemli olacak $\mathrm{m} 1$ sorularının da cevaplanması gerekmektedir. Bundan sonraki kısımda bu soruların ideal bir akıllı ev sistemine göre cevapları ve cevaplarına göre hangi yöntemin hangi durumda avantajlı ya da dezavantajlı olacağı sunulacaktır.

Bir akıllı ev sistemini en azından aynı evde yaşayan birden fazla kişi olacağı ya da bir evde bir kişi bulunsa dahi farklı evlerde kullanılabilecek bir akıllı ev sistemi olacağı için konuşma tanıma işleminin konuşmacıdan bağımsız olarak farklı kişileri desteklemesi uygun olacaktır. Ayrıca konuşma tanımanın yanında sistemin konuşan kişinin kim olduğunu tanıyabilmesi de ileriye dönük iyi bir ek özellik olacaktır. Komut sayısı ele alındığında ise akıllı ev sisteminde kullanılabilecek sınırlı sayıda sesli komut tüm 
işlemlerin gerçekleştirilmesi için yeterli olacaktır. Ancak daha gelişmiş bir sistem geliştirilmek istendiği takdirde akıcı bir konuşma içinde farklı şekilde söylenebilecek komutları algılayabilecek bir konuşma tanıma sistemi de gerekebilir. İnternet bağlantısı yönünden durum incelendiğinde; artık gelişmiş ülkelerin birçoğunda hemen her yerde internet bağlantısı olduğu için sistemin internete bağlı olmasının gerekmesi herhangi bir sorun teşkil etmeyecektir [19]. Bununla birlikte internet bağlantısı gerektirmeyen bir konuşma tanıma sistemi geliştirilmek istenirse internet tabanlı bulut hizmetlerden faydalanılamayacaktır. Son olarak donanımların işlem kapasiteleri ile enerji ihtiyaçlarının ters orantılı olduğu söylenebilir. Konuşma tanıma işleminin hızlı bir şekilde gerçekleştirilebilmesi için daha hızlı donanımlara ihtiyaç duyulacaktır. Ayrıca komut sayısı arttıkça daha fazla depolama alanına ve daha fazla işlem gücü de gerekecektir.

\subsection{Konuşma tanıma yöntemleri ve ihtiyaçlara göre avantaj \& dezavantajları}

Konuşma tanıma yapabilmek dolayısıyla akı1lı evlerin sesli komutlarla yönetilebilmesini sağlamak için temel yöntem olarak; en baştan başlanarak ses mikrofon ile alınarak bilgisayara aktarılıp, öznitelik vektörü çıkartılıp belirli bir veri seti oluşturulabilir. Bununla birlikte hâlihazırda oluşturulmuş çeşitli dillere özgü veri setleri de bulunmaktadır. Ancak yapılan araştırmalarda İngilizce, İspanyolca, Çince vb. birçok dil için genel kullanıma açık veri setleri bulunmasına karşın Türkçe dilinde genel kullanıma açık herhangi bir veri setine rastlanamamıştır [20]. Dolayısıyla konuşmacıdan bağımsız ve çok sayıda komutun algılanabildiği bir konuşma tanıma sistemi için hazır veri seti olan dilleri destekleyen bir akıllı ev sistemi uygun olacaktır. Türkçe komutlar ile çalışabilen bir sistem isteniyor ise komut sayısının azaltılması ve konuşmacı bağımlı olması araştırma geliştirme sürecini kolaylaştıracaktır. Sonuç olarak bu yöntem hazır veri seti olan diller için ya da az sayıda komutla yönetilebilecek konuşmacı bağımlı oluşturulacak sesli komut sistemleri için uygundur. Kullanılabilecek yöntemler açısından durum incelendiğinde ise öznitelik vektörü çıkarmak için en çok kullanılan yöntemin MMFC, sınıflandırma içinse en iyi yöntemin HMM ya GHM olduğu belirlenmiştir [21].

En temelden başlayarak bütün yöntemlerin algoritmalarını yazmak oldukça uzun zaman ve yüksek düzeyde emek gerektirecektir. Bunun yerine hâlihazırda geliştirilmiş açık kaynak olarak kullanıma açılmış yapay zekâ kütüphaneleri ile konuşma tanıma için özelleştirilmiş kütüphaneler kullanmak zaman ve emek açısından tasarruf sağlayacaktır. Sınıflandırma için en iyi yöntemin HMM olduğu düşünüldüğünde hazır kütüphaneler arasından HTK (Hidden Markov Toolkit) konuşma tanıma için en uygun seçeneklerden biri olacaktır [22]. Ayrıca konuşma tanıma algoritmalarından yüksek performans beklendiği durumlarda yapay zekâ çalışmaları için özelleştirilmiş Nvidia Jetson vb. donanımlar da kullanılabilir [23].

Akıllı evlerde konuşma tanıma işlem için kullanılabilecek kişilerin geliştirebileceği ve eğitebileceği algoritmalar yanında belirlenen sesli komutları algılayan çeşitli donanımlar ve yazılımlar da bulunmaktadır. Bu donanımlar ve yazılımlar kullanılırken öncelikle tanınması istenen sesli komutlar donanıma ve yazılıma konuşularak tanıtılır. Daha sonra gerekli kodlar algılandığında yapılması gereken işlemler belirtilir ve donanım ya da yazılım kendi içerisinde yer alan algoritmalar sayesinde alınan ses komutlarını daha önce kaydedilen ses komutları ile eşleştirerek işlemi gerçekleştirir [23,24,25]. Örneğin günümüzde artık birçok çalışmada kullanılan Arduino' ya eklenti olarak geliştirilen EasyVR Shield ile 28 adet konuşmacıdan bağımsız hazır komut ve 32 adet konuşmacıya 
bağımlı geliştirici tarafindan belirlenecek komut, konuşma tanıma için kullanılabilmektedir. Özellikle ufak çaplı çalışmalarda, çok fazla sesli komutun gerekmediği, hızlı ve kolay bir konuşma tanıma sistemi gerektiğinde bu yöntem oldukça avantajlıdır.

Konuşma tanıma için kullanılabilecek belki de en kolay ve basit yöntem internet bağlantısının bulunduğu noktalarda bulut hizmetlerinden yararlanmaktır. Google, Microsoft vb. firmalar, geliştirdikleri konuşma tanıma alt yapılarını internet üzerinden bulut mimarisinde kullanıcilara sunmaktadır. Kullanıcılar bu sistemlerin API'lerini (Application Programming Interface) kullanarak sesli komutları öncelikle internette bulut servislere gönderirler. Bulut serviste cevap olarak verilen sesli komutun ne olduğunu yazılı olarak geri döndürür [26,27]. Ayrıca bulut hizmetler çok fazla sayıda (Türkçe dâhil) dili desteklemektedir. Bu tür bulut sistemler her komutu algılamalarına karşın çeşitli noktalarda eksiklikleri vardır. Örneğin bir termostatın derecesini belirli bir değere ayarlamak için kullanıcının kuracağı cümlelerde farklılıklar olabilir. $\mathrm{Bu}$ tür durumlar için verilen komutların ne olduğunu algılayan ve ona göre ses tanımanın yanında komutu içerik olarak işleyerek geriye değer döndüren servislerde mevcuttur (api.ai, 2017). Örneğin api.ai kullanıcı "termostatı 25 dereceye ayarla" diyerek komut verdiğinde sistem geri şöyle bir yanıt döndürmektedir (şu anda Türkçe desteği yoktur):

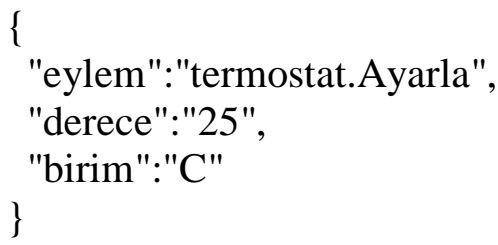

$\mathrm{Bu}$ JSON biçiminde dönen yanıt sonucunda akıllı evde ne yapılması isteniyorsa kolaylıkla yapılabilir [28]. Bu yöntemin her ne kadar Türkçe dil desteği bulunmasa da farklı iki yöntemi kullanarak bu sorun aşılabilir. Öncelikle bir bulut servis kullanılarak sesli komut metne dönüştürülür, daha sonra doğal dil işleme için özelleştirilmiş api.ai benzeri bir kütüphane olan wit.ai farklı tarzda söylenen komutlar için eğitilerek konuşma tanıma için kullanılabilir [29].

İnternet bağlantısının bulunduğu durumlarda yazılımsal olarak kullanılabilecek en kolay yöntem bulut hizmetleridir. Bunun yanında mikrofon ve hoparlörü bulunan, bütün konuşma tanıma işlemlerini kendisi bulut servisine bağlanarak yapan donanımları kullanmak ise bir akıllı evde kullanılabilecek donanımsal en kolay yöntemdir. Örneğin Amazon Echo kullanılarak bir odada yapılan konuşmaların metin halleri bu donanımın API dosyası (uygulama programlama ara yüzü) kullanılarak alınabilir ve ona göre geliştirilecek olan sistemde gerekli işlemler yapılabilir [30].

\section{Sonuçlar}

$\mathrm{Bu}$ çalışma ile akıllı evler geliştirenlere ve bu konuda araştırma yapanlara bir akıllı evin sesli komutlar ile yönetilebilmesi için hangi yöntemlerin kullanılabileceği ve yöntemlerin birbirine göre avantaj ve dezavantajları sunulmuştur. Sonuç olarak eğer İngilizce bir konuşma tanıma sistemi yeterli ise api.ai gibi konuşmada farklı şekillerde söylenebilecek komutları JSON formatında anlamlı verilere dönüştürerek geri döndüren bir servisi kullanmak en doğru tercih olacaktır. Eğer Türkçe komutlar ile çalışan bir 
sistem geliştirmek isteniyor ise bunun için uygun yöntem; ilk olarak farklı yaş gruplarında ve cinsiyetteki insanlardan tanınması istenen komutlarla ilgili farklı söylenişlerde konuşma verileri toplanmalı, daha sonra bu toplanan veriler ile HTK vb. konuşma tanıma için özelleştirilmiş ya da özelleştirilebilir bir kütüphane eğitilmeli ve son olarak eğitilen bu kütüphane ile api.ai' de olduğu gibi konuşma verilerini anlamlı bir biçime dönüştürecek algoritma oluşturulmalıdır.

\section{Kaynaklar}

[1] Y1lmaz, H., Akıllı ev'in dünyadaki ve Türkiye'deki yeri, Bina Elektrik, Elektronik, Mekanik ve Kontrol Sistemleri Dergisi, (2004).

[2] McDonald, C.W., Talk to your house with these voice-activated smart-home systems, (2015). https://www.cnet.com/news/talk-to-your-house-with-thesevoice-activated-smart-home-systems/, (14.08.2017).

[3] Gelegin, İ. ve Bolat, B., Ayrık kelime tabanlı bir konuşma tanıma sistemiyle bilgisayar kontrolü, Elektrik-Elektronik ve Bilgisayar Sempozyumu, Elazığ, 2011.

[4] Gürel, A. ve Arslan, L.M., Konuşma tanıma için insan-makine karşılaştırması, Dilbilim Araştırmaları, (2008).

[5] Yusnita, M.A., Paulraj, M.P., Yaacob, S., Abu Bakar, S., Saidatul, A., Abdullah, A.N., Phoneme-based or 1solated-word modeling speech recognition system? an overview, International Colloquium on Signal Processing and its Applications, Penang, (2011).

[6] Rana, M. ve Saloni, E., A review on automatic speech recognition system, International Journal Of Engineering And Computer Science, 9849-9852, (2015).

[7] Nugues, P., An overview of speech synthesis and recognition, Language Processing with Perl and Prolog, Springer, 1-3, (2014).

[8] Jarande, S.S. ve Waghmare, S., A survey on different classifier in speech recognition techniques, International Journal of Emerging Technology and Advanced Engineering, 534-539, (2014).

[9] Comparing Top Deep Learning Frameworks: Deeplearning4j, Torch, Theano, TensorFlow, Caffe, Paddle, MxNet, Keras \& CNTK, (2017). https://deeplearning4j.org/compare-dl4j-torch7-pylearn.html\#comparing-topdeep-learning-frameworks-deeplearning4j-torch-theano-tensorflow-caffepaddle-mxnet-keras--cntk, (11.08.2017).

[10] Top 5 Open Source Speech Recognition Toolkits, (2016). http://blog.neospeech.com/top-5-open-source-speech-recognition-toolkits/, (14.08.2017).

[11] RSC-4X Family of Speech Recognition And Synthesis Microcontrollers, (2017). http://www.sensory.com/products/integrated-circuits/rsc-4x-series/, (14.08.2017).

[12] HM2007, (2007). http://www.imagesco.com/speech/HM2007.pdf, (15.08.2017).

[13] Speech Recognition Reference Design on the C5535 eZdsp(TM), (2016). http://www.ti.com/tool/tidep0066, (14.08.2017). 
[14] EasyVR Shield 3.0 - Voice Recognition Shield, (2017). https://www.sparkfun.com/products/13316, (14.08.2017).

[15] The ES6929P - Stand Alone Speech Recognition For Arduino, (2015). https://www.kickstarter.com/projects/172204344/the-es6929p-stand-alonespeech-recognition-for-ard, (14.08.2017).

[16] Shmyrev, N., What are the top ten speech recognition APIs?, (2016). https://www.quora.com/top-ten-speech-recognition-APIs, (14.08.2017).

[17] Crist, R., Talk to your house with these voice-activated smart-home systems, (2015). https://www.cnet.com/news/talk-to-your-house-with-these-voiceactivated-smart-home-systems/, (14.08.2017).

[18] SpeechRecognition, (2017). https://pypi.python.org/pypi/SpeechRecognition/, (14.08.2017).

[19] Internet Access, (2017). https://data.oecd.org/ict/internet-access.htm, (14.08.2017).

[20] Open Speech and Language Resources, (2017). http://www.openslr.org/resources.php, (14.08.2017).

[21] Gaikwad, S.K., Gawali, B.W. ve Yannawar, P., A review on speech recognition technique, International Journal of Computer Applications, 16-24, (2010).

[22] What is HTK?, (2016). http://htk.eng.cam.ac.uk/, (14.08.2017).

[23] NVIDIA Jetson TX2: The New Gold Standard for AI at the Edge, (2017). https://news.developer.nvidia.com/introducing-the-nvidia-jetson-tx2-the-newgold-standard-for-ai-at-the-edge/, (14.08.2017).

[24] MOVI ${ }^{\mathrm{TM}}$ Arduino Shield, (2016). http://www.audeme.com/movi.html, (16.05.2017).

[25] Integrate Dragon speech recognition into your applications, (2017). https://www.nuance.com/dragon/for-developers/dragon-software-developerkit.html, (10.08.2017).

[26] Cloud Speech Api, (2017). https://cloud.google.com/speech/, (14.08.2017).

[27] Bing Speech Api, (2017). https://azure.microsoft.com/en-us/services/cognitiveservices/speech/, (14.08.2017).

[28] Smart Home, (2017). https://api.ai/, (14.08.2017).

[29] Natural Language for Developers, (2017). https://wit.ai/, (25.05.2017).

[30] Echo \& Echo Dot, (2017). https://developer.amazon.com/echo, (22.08.2017). 